\title{
Hyperchaotic circuit with damped harmonic oscillators
}

\author{
Lindberg, Erik; Murali, K.; Tamasevicius, A.
}

Published in:

Proceedings on The 2001 IEEE International Symposium on Circuits and Systems

Link to article, DOI:

10.1109/ISCAS.2001.921443

Publication date:

2001

Document Version

Publisher's PDF, also known as Version of record

Link back to DTU Orbit

Citation (APA):

Lindberg, E., Murali, K., \& Tamasevicius, A. (2001). Hyperchaotic circuit with damped harmonic oscillators. In Proceedings on The 2001 IEEE International Symposium on Circuits and Systems (Vol. 2, pp. 759-762) https://doi.org/10.1109/ISCAS.2001.921443

\section{General rights}

Copyright and moral rights for the publications made accessible in the public portal are retained by the authors and/or other copyright owners and it is a condition of accessing publications that users recognise and abide by the legal requirements associated with these rights.

- Users may download and print one copy of any publication from the public portal for the purpose of private study or research.

- You may not further distribute the material or use it for any profit-making activity or commercial gain

- You may freely distribute the URL identifying the publication in the public portal 


\title{
HYPERCHAOTIC CIRCUIT with
}

\section{DAMPED HARMONIC OSCILLATORS}

\author{
E.Lindberg (1), K.Murali (2), A.Tamasevicius (3) \\ (1) Ørsted DTU Dpt. , 348 Technical University of Denmark, Kgs. Lyngby, DK 2800, Denmark, \\ (2) Department of Physics, Anna University, Chennai - 600 025, India, \\ (3) Semiconductor Physics Institute, A.Gostauto 11, Vilnius, LT 2600, Lithuania
}

\begin{abstract}
A simple fourth-order hyperchaotic circuit with damped harmonic oscillators is described. ANP3 and PSpice simulations including an eigenvalue study of the linearized Jacobian are presented together with a hardware implementation. The circuit contains two inductors with series resistance, two ideal capacitors and one non-linear active conductor. The Lyapunov exponents are presented to confirm the hyperchaotic nature of the oscillations of the circuit. The non-linear conductor is realized with a diode. a negative impedance converter and a linear resistor. The performance of the circuit is investigated by means of numerical integration of the appropriate differential equations.
\end{abstract}

\section{INTRODUCTION}

Hyperchaotic oscillations are defined as having more than one positive Lyapunov exponents (LE). Several 4'th order hyperchaotic oscillators and circuits characterized by 2 positive Lyapunov exponents have been reported [1-12]. The increasing interest in hyperchaotic oscillators is stimulated by their possible application to secure communications [12-14]. In order to obtain hyperchaotic oscillations from an electronic circuit it should be at least either a 4 'th order one in the case of common passive nonlinearity, e.g. produced by diodes [4-6, 8-11]. or a 3'rd order one in the case of a hysteretic nonlinearity [3]. In 1997 a simple 4 'th order hyperchaotic oscillator based on non-linear coupling of two linear oscillators was proposed [4]. It consists of a linear stable resonance circuit with high $Q$ and a linear unstable resonance circuit with low $Q$. These two resonance circuits are coupled by means of a diode. Further simple hyperchaotic circuits with unstable oscillators coupled by a non-linear device have been studied $[9,10]$. However, almost all the hyperchaotic circuits proposed so far contain at least one unstable or active oscillator in the circuitry. Recently it was demonstrated that two unstable active linear negative resistance oscillators coupled by two diodes in anti parallel may control each other and show hyperchaotic performance with jumping between two chaotic attractors [6]. Unfortunately the circuit is difficult to realize in practice and the result becomes limit cycle behaviour controlled by the output swing of the op. amps.

Please note that active oscillators may be defined as amplifiers with unstable DC bias points.

In order to overcome the problem with coupling of active oscillators a hyperchaotic circuit containing stable oscillators coupled by an active non-linear conductor is suggested. The nonlinear conductor composite is realized with a general-purpose diode, a negative impedance converter (NIC) and a linear resistor. The purpose of the NIC is to produce negative slope in the characteristic of the non-linear composite. This kind of configuration provides good temperature stability and better reproducibility of the hyperchaotic circuit. Also a linear series buffer resistor is included in the non-linear resistor circuit so that lower sensitivity to the manufacturing spread of the diode parameters is obtained.

\section{CIRCUIT DESCRIPTION}

\subsection{Circuit Diagram}

The circuit diagram of the hyperchaotic circuit is shown in Fig.1.

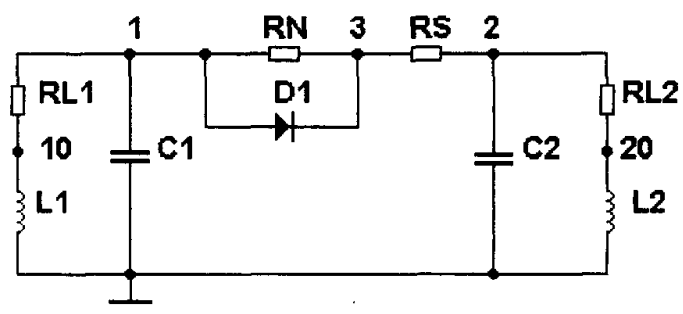

Figure 1. Fourth-order hyperchaotic circuit with damped RLC oscillators.

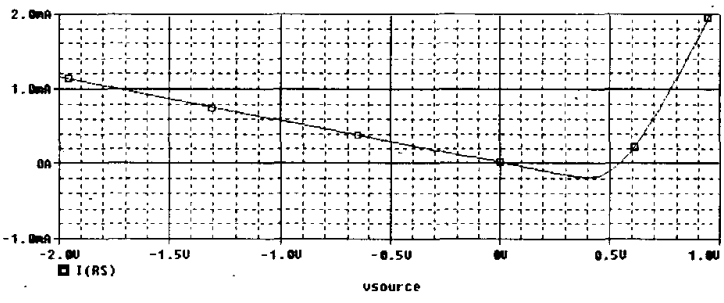

Figure 2. Characteristic IGN $=f(V G N)$ of the non-linear conductor composite between node 1 and node 2 (PSpice calculation with diode $1 \mathrm{~N} 4148$ and op amp uA741). The slopes in the two almost linear regions correspond to $1.75 \mathrm{k} \Omega$ and $+162.5 \Omega$. 
This circuit consists of two linear resonance circuits, (L1, RL1, C1) and (L2, RL2, C2) coupled by means of a non-linear conductor GN. The non-linear conductor is realized by a resistor $\mathrm{RS}$ in series with a parallel combination of a negative impedance converter (NIC, RN in Fig.1) and a general-purpose diode e.g. 1N4148. The current-voltage characteristic curve of the nonlinear conductor is depicted in Fig. 2.

\subsection{Circuit Equations}

The dynamics of circuit in Fig. 1 are described by Eqns.(1):

$$
\begin{aligned}
& \mathrm{C} 1 \times \mathrm{d} / \mathrm{dt}(\mathrm{VC} 1)=-\Pi 1+\mathrm{IGN} \\
& \mathrm{L} 1 \times \mathrm{d} / \mathrm{dt}(\amalg 1)=+\mathrm{VC} 1-\mathrm{RL} 1 \times \amalg \mathbf{I} \\
& \mathrm{C} 2 \times \mathrm{d} / \mathrm{dt}(\mathrm{VC} 2)=-\mathrm{IL} 2-\mathrm{IGN} \\
& \mathrm{L} 2 \times \mathrm{d} / \mathrm{dt}(\mathrm{IL} 2)=+\mathrm{VC} 2-\mathrm{RL} 2 \times \amalg 2
\end{aligned}
$$

where VC1, VC2, IL1 and IL2 are the state variables (voltages of $\mathrm{C} 1, \mathrm{C} 2$ and currents of $\mathrm{L} 1, \mathrm{~L} 2)$.' Please note that $\mathrm{IGN}=\mathrm{f}(\mathrm{VC} 1-$ VC2) is a non-linear function of the capacitor voltages. For simplicity, a two-segment piecewise linear model for the device $\mathrm{GN}$, is represented as

$$
\begin{aligned}
& I G N=\mathrm{f} 1(V G N)=G a \times V G \quad \text { for } V G N \leq B p \\
& I G N=f 2(V G N)=G b \times V G N+(G a-G b) \times B p
\end{aligned}
$$$$
\text { for } \mathrm{VGN} \geq \mathrm{Bp}
$$

where $\mathrm{Ga}, \mathrm{Gb}$ and $\mathrm{Bp}$ are the negative slope, the positive slope and the break-point voltage respectively.

Here $B p=0.65 \mathrm{~V}$ and $\mathrm{Rd}=25 \Omega$ at $5 \mathrm{~mA}$ are fixed from the diode parameters (e.g. 1N4148).

By introducing the following set of notations

$$
\begin{aligned}
& \mathrm{x}=\mathrm{VC} 1 / \mathrm{Bp} . \quad \mathrm{y}=\rho \times \Pi \mathbf{L} 1 / \mathrm{Bp} . \quad \mathrm{z}=\mathrm{VC} 2 / \mathrm{Bp} . \\
& \omega=\rho \times \Pi 2 / \mathrm{Bp} . \quad \rho=\sqrt{ }(\mathrm{L} 1 / \mathrm{C} 1) . \\
& \tau=\sqrt{ }(\mathrm{L} 1 \times \mathrm{C} 1) . \quad \varepsilon=\mathrm{C} 2 / \mathrm{C} 1 . \\
& \mu=\mathrm{L} 2 / \mathrm{L} 1 . \quad \mathrm{R}=\mathrm{RN} \times \mathrm{Rd} /(\mathrm{RN}+\mathrm{Rd}) . \\
& \mathrm{Ga}=1 /(\mathrm{RN}+\mathrm{RS}) . \quad \mathrm{Gb}=1 /(\mathrm{R}+\mathrm{RS}) . \\
& a=\rho /(R N+R S), \quad b=\rho /(R+R S) . \quad \theta=t / \tau . \\
& \mathrm{du} / \mathrm{dt}=(1 / \tau)(\mathrm{du} / \mathrm{d} \theta), \quad \mathrm{d}=1-\mathrm{RS} /|\mathrm{RN}| .
\end{aligned}
$$

we obtain the following set of differential equations describing the dynamics of the circuit Fig.1 as Eqns.(2):

$$
\begin{aligned}
& \mathrm{dx} / \mathrm{dt}=-\mathrm{y}-\mathrm{f}(\mathrm{x}-\mathrm{z}) \\
& \mathrm{dy} / \mathrm{dt}=\mathrm{x} \\
& \varepsilon^{\times} \mathrm{dz} / \mathrm{dt}=-\omega+\mathrm{f}(\mathrm{x}-\mathrm{z}) \\
& \mu \times \mathrm{d} \omega / \mathrm{dt}=\mathrm{z}
\end{aligned}
$$

where

$$
f(x-z)=a \times x+0.5 \times b \times[a b s(x-z-d)+(x-z-d)]
$$

\section{NUMMERICAL SIMULATIONS}

\subsection{Equations and Lyapunov exponents}

The dynamics of circuit as shown in Fig.1 are studied by numerical integration of the normalized differential equations. In order to check whether the circuit is hyperchaotic, the Lyapunov exponents of the system have been computed.

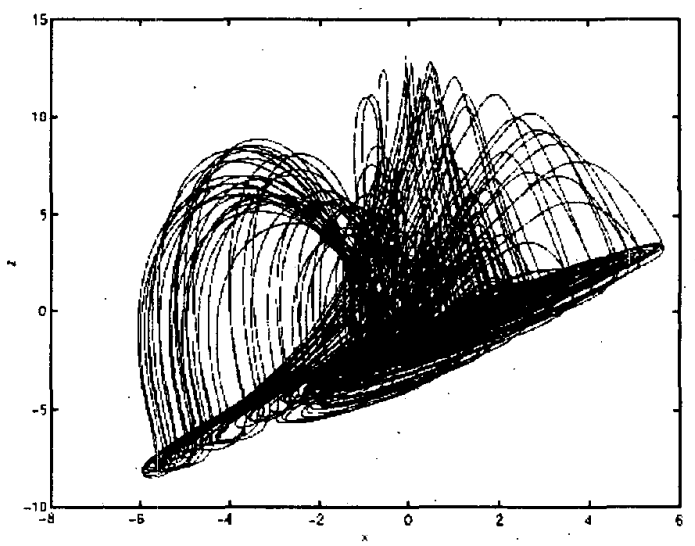

Figure 3. Hyperchaotic attractor observed from the circuit of Fig.1. Projection onto the (x-z)-plane. Attractor observed by numerical simulation of Eqns.(2) for $\varepsilon=0.31, \mu=0.33 . a=-0.62 \mathrm{e}-3$ and $b=6.0 \mathrm{e}-3$

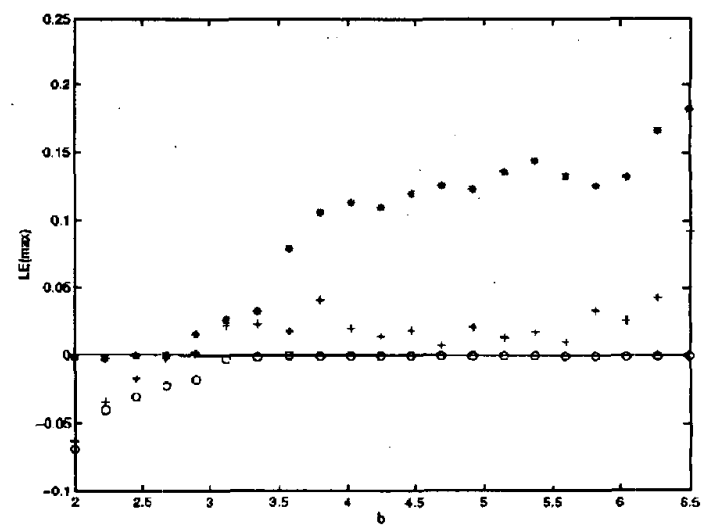

Figure 4. Three largest Lyapunov exponents against parameter $b$

The circuit parameters of Fig. 1 are fixed as $\mathrm{Cl}=220 \mathrm{nF}, \mathrm{Ll} 1=$ $256 \mathrm{mH}, \mathrm{RL} 1=15 \Omega, \mathrm{C} 2=68 \mathrm{nF}, \mathrm{L} 2=84 \mathrm{mH} . \mathrm{RL} 2=7.5 \Omega, \mathrm{RS}=$ $1 \mathrm{k} \Omega$ (adjustable). $\mathrm{RN}=-1900 \Omega$ and $\mathrm{Rd}=25 \Omega$. For these: parameters the normalized values are calculated as $\varepsilon=0.31, \mu=$ : 0.33 and $a=-0.62 \mathrm{e}-3$. A typical phase-portrait is shown in Fig.3 for $b=6.0 \mathrm{e}-3$ and $\mathrm{RS}=155 \Omega$. 
The Lyapunov exponents characterizing the stability properties of the non-linear circuit have been computed from Eqns.(2). Fig. 4 depicts the three maximal Lyapunov spectrum $\left(\lambda_{\max }\right.$ versus b) in which two maximal Lyapunov exponents are positive for certain values of $\mathbf{b}$ indicating the hyperchaotic nature of circuit oscillations of Fig.1.

\subsection{ANP3 and PSpice simulations}

In recent years, circuit simulators such as PSpice have been used for the simulation of the chaotic circuits. PSpice simulations of the hyperchaotic circuit (Fig.1) were carried-out using $\mathrm{Cl}=$ $220 \mathrm{nF}, \mathrm{L} 1=256 \mathrm{mH}, \mathrm{RL1}=15 \Omega, \mathrm{C} 2=68 \mathrm{nF}, \mathrm{L} 2=84 \mathrm{mH}, \mathrm{RL} 2$ $=7: 5 \Omega, \mathrm{RS}=155 \Omega$ and $\mathrm{RN}=-1900 \Omega$.

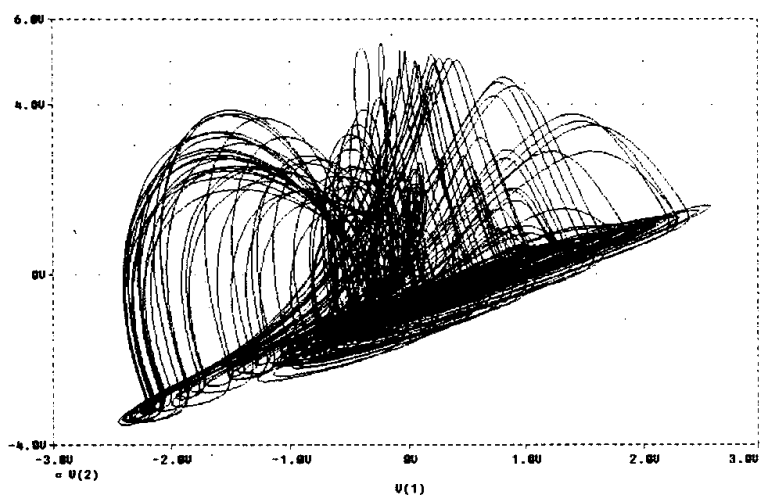

Figure 5. PSpice simulation result: Hyperchaotic attractor observed from the circuit of Fig.1. Projection onto the (VC1-VC2)-plane

For the implementation of the non-linear element GN, a negative impedance $(-\mathrm{RN})$ is connected in parallel with a diode $\mathrm{D} 1$ (e.g. $1 \mathrm{~N} 4148, \mathrm{Bp}=0.65 \mathrm{~V}, \mathrm{Rd}=25 \Omega$ at $5 \mathrm{~mA}$ ) and a linear resistor $\mathrm{RS}$ is connected in series with the (RN-D1)-parallel combination. The VC2 as function of VC1 trajectory is shown in Fig.5 for RS $=155 \Omega$. There is good agreement between the numerical simulation (Fig.3) and the PSpice simulation results.

ANP3 results with $1 \mathrm{N4148}$ and $\mu$ A741 small signal macro models

$$
\begin{aligned}
& \langle 22\rangle \quad \mathrm{R} 20 \quad-1.75 \mathrm{e}+3 \\
& \text { POLES Sigma j*Omega Q } \mathrm{f} \mathrm{Hz} \\
& \text { P } \quad 1.44666 \mathrm{D}+03 \quad-4.32800 \mathrm{D}+03 \quad-1.6 \quad-6.89 \mathrm{D}+02 \\
& \begin{array}{lllll}
P & 1.44666 \mathrm{D}+03 & 4.32800 \mathrm{D}+03 & -1.6 & 6.89 \mathrm{D}+02
\end{array} \\
& \begin{array}{lllll}
\text { P } & 3.98097 \mathrm{D}+03 & -1.14683 \mathrm{D}+04 & -1.5 & -1.83 \mathrm{D}+03
\end{array} \\
& \begin{array}{lllll}
P & 3.98097 \mathrm{D}+03 & 1.14683 \mathrm{D}+04 & -1.5 & 1.83 \mathrm{D}+03
\end{array} \\
& \begin{array}{llllll}
\langle 16\rangle & R 202 & 0 & +162.5 \\
\text { POLES Sigma } & j^{*} \text { Om egg } & Q & f \mathrm{~Hz} \\
\mathrm{P} & -5.49217 \mathrm{D}+02 & 0.00000 \mathrm{D}-01 & 0.50 & 0.00 \mathrm{D}-01 \\
\mathrm{P} & -1.17296 \mathrm{D}+05 & 0.00000 \mathrm{D}-01 & 0.50 & 0.00 \mathrm{D}-01 \\
\mathrm{P} & -3.85135 \mathrm{D}+02 & -7.39772 \mathrm{D}+03 & 9.6 & -1.18 \mathrm{D}+03 \\
P & -3.85135 \mathrm{D}+02 & 7.39772 \mathrm{D}+03 & 9.6 & 1.18 \mathrm{D}+03
\end{array}
\end{aligned}
$$

Introducing the linear values of the total resistance between node 1 and node 2 (Fig.2) ANP3 simulations gives the pole placements in the two regions [15]. It is seen that in the region with $-1.75 \mathrm{k} \Omega$ we have two complex pole pairs in RHP corresponding to the two positive Lyapunov exponents and in the region with $+162.5 \Omega$ we have a complex pole pair and two real poles in LHP. As expected [5] we observe a very large negative real root $(-1.226 \mathrm{E}+5)$. The mechanism behind the chaotic behaviour seems to be the rapid switching between two complex poles in RHP and a large real pole in LHP.

ANP3 results with ideal op amp model and perfect diode model:

$$
\begin{aligned}
& \langle 45\rangle: D 103 \text { D1N4148 : diode OFF, GD=0 } \\
& \text { POLES Sigma j*Omega } Q \text { f Hz } \\
& \text { P } \quad 1.45216 \mathrm{D}+03 \quad-4.32894 \mathrm{D}+03 \quad-1.6 \quad-6.89 \mathrm{D}+02 \\
& \text { P } \quad 1.45216 \mathrm{D}+03 \quad 4.32894 \mathrm{D}+03 \quad-1.6 \quad 6.89 \mathrm{D}+02 \\
& \text { P } \quad 3.99123 \mathrm{D}+013-1.14570 \mathrm{D}+04-1.5 \quad-1.82 \mathrm{D}+03 \\
& \begin{array}{lllll}
\text { P } & 399123 \mathrm{D}+03 & 1.14570 \mathrm{D}+04 & -1.5 & 1.82 \mathrm{D}+03
\end{array} \\
& <75>\text { RD1 } 030.5664: \text { diode } 014 \\
& \text { POLES Sigma } j^{*} \text { Omega } Q \quad f ~ H z \\
& \begin{array}{lllll}
P & -5.28152 \mathrm{D}+02 & 0.00000 \mathrm{D}-01 & 0.50 & 0.00 \mathrm{D}-01
\end{array} \\
& \begin{array}{llllll}
\mathrm{P} & -1.22627 \mathrm{D}+05 & 0.00000 \mathrm{D}-01 & 0.50 & 0.00 \mathrm{D}-01
\end{array} \\
& \begin{array}{lllll}
\mathrm{P} & -3.70244 \mathrm{D}+02 & -7.39858 \mathrm{D}+03 & 10 . & -1.18 \mathrm{D}+03
\end{array} \\
& \text { P } \quad-3.70244 \mathrm{D}+02 \cdot 7.39858 \mathrm{D}+03 \text { 10. } 1.18 \mathrm{D}+03
\end{aligned}
$$

\section{Spectrum for V(1) and V(2), Pspice}

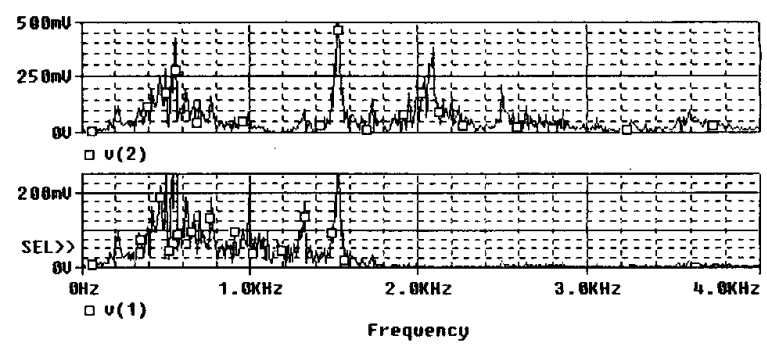

\section{HARDWARE EXPERIMENTS}

The circuit has been built in hardware (Fig. 6).

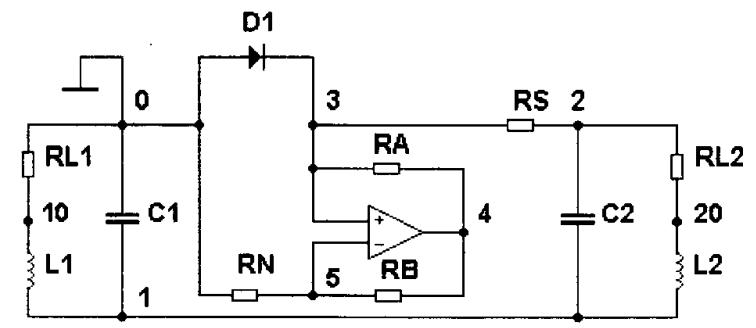

Figure 6. Hardware implementation. Please note that node 1 and the reference node are switched because the negative resistor is a three terminal element. 
The structure proposed by Matsumoto et.al. [2] contains 2 op amps, 2 diodes, 2 ideal coils, 2 ideal capacitors and 8 resistors i.e. 1 grounded active resonator, 1 floating passive resonator and 1 grounded active nonlinear coupling.

The structure proposed here by Lindberg et.al. contains 1 op amp, 1 diode, 2 coils with loss resistors, 2 ideal capacitors and 4 resistors i.e. 1 grounded passive resonator, 1 floating passive resonator and 1 grounded active nonlinear coupling.

Fig. 7 shows the result with LM301AJ as op amp (compensation capacitor $40 \mathrm{pF}$ ) and $1 \mathrm{~N} 4148$ as diode. Laboratory decade boxes used for the coils and capacitors. RL1 measured to $14.8 \Omega$ and $\mathrm{RL} 2$ measured to $7.2 \Omega . \quad \mathrm{RA}=85.0 \Omega, \quad \mathrm{RB}=80.7 \Omega, \quad \mathrm{RN}=$ $1901 \Omega$ and $R S=155.8 \Omega$. The negative resistance become Rneg $=-\mathrm{RN} \times \mathrm{RA} / \mathrm{RB}=-2 \mathrm{k} \Omega$ if ideal op amp is assumed. Close agreement with PSpice simulations has been found.

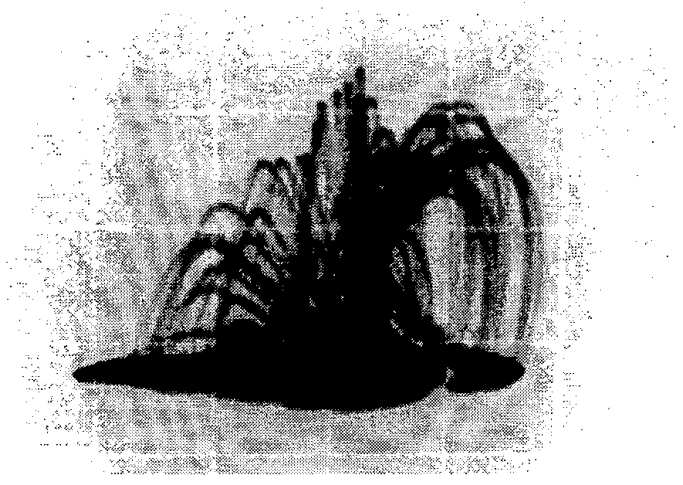

Figure 7. Oscilloscope: $y=V(2), x=V(1)$ with $R A=$ $85.0 \Omega$ and $R B=80.7 \Omega$. Scale: $x$ unit $=1 \mathrm{~V}$. $y$ unit $=2 \mathrm{~V}$.

\section{CONCLUSIONS}

We have designed and investigated a damped linear oscillators based fourth-order hyperchaotic circuit. Two positive Lyapunov exponents characterize the circuit's oscillations. Due to the usage of stable oscillators coupled through a non-linear resistor. this circuit has better reproducibility, and higher stability. Further due to the inclusion of a large buffer resistor RS, the circuit has lower sensitivity to the manufacturing spread of the diode parameters. Also this circuit can be experimentally realized easily and further can be used for synchronization and ensuing secure communication applications.

\section{Acknowledgement}

K. Murali is grateful to The Institute of Mathematical Sciences. Chennai, INDIA for providing the computational facilities.

The constructive comments of the reviewers of this paper are acknowledged.

\section{REFERENCES}

[1] O.E. Rössler, "An equation for hyperchaos", Phys.Lett., vol. 71, 1979, pages 155-157.

[2] T. Matsumoto, L.O. Chua, K.Kogayashi, "Hyperchaos: laboratory experiment and numerical confirmation", IEEEE Trans. Circuits and Systems, vol. CAS-33, 1986, pages 1143-1147.

[3] T. Saito, "An approach towards higher dimensional hysteretic chaos generators", IEEE Trans. Circuits and Systems-1, vol. CAS-37, 1990, pages 399-409.

[4] A. Tamasevicius, A. Cenys, G. Mykolaitis, A. Namajunas, E. Lindberg. "Hyperchaotic oscillator with gyrators", Electronics Letters, vol. 33, 1997, pages 542-544.

[5] E. Lindberg, "Oscillators and Eigenvalues", Proceedings ECCTD'97 - The 1997 European Conference on Circuit Theory and Design, Budapest, September 1997, ISBN-963420-5232, pp.171-176.

[6] E. Lindberg, " Chaotic Oscillator Design ", Seminar notes, Seminar at Competence Centre for Circuit Design, Department of Applied Electronics, Lund University, Ole Römers väg 3, P.O. Box 118, SE-221 00 Lund, Sweden, 2000.06.20

[7] A. Tamasevicius, "Hyperchaotic circuits: state of the art", NDES-97 Proceedings 5'th International Workshop on Nonlinear Dynamics of Electronic Systems, 1997, pages 97102.

[8] A. Tamasevicius, A. Cenys, "Hyperchaos in dynamical systems with a monoactive degree of freedom", Chaos, Solitons and Fractals, vol. 9, 1998, pages 115-119.

[9] K. Murali, A. Tamasevicius, E. Lindberg,. "Unstable oscillators based hyperchaotic circuit", NDES-99 Proceedings 7'th International Workshop on Non-linear Dynamics of Electronic Systems. 1999, Pages 241-244.

[10] K. Murali. A. Tamasevicius, G. Mykolaitis, A. Namajunas, E. Lindberg. "Hyperchaotic circuits with unstable oscillators". Nonlinear Phenomena in Complex Systemes, vol.3, 2000, pages 7-10.

[11] A. Tamasevicius, A. Cenys, G. Mykolaitis, A. Namajunas, E. Lindberg. "Synchronization of hyperchaotic oscillators", Electronics Letters, vol. 33, 1997, pages 2025-2026.

[12] A. Tamasevicius. A. Cenys, "Synchronizing hyperchaos with a single variable", Phys.Rev. E, vol. 55, 1997, pages 297-299.

[13] L.Kocarev, U.Parlitz, "General approach for chaotic synchronization with applications to communication", Phys. Rev. Lett., vol. 74, 1995, pages 5028-5031.

[14] J. Peng, E.J. Ding, M. Ding, W. Yang, "Synchronizing hyperchaos with a scalar transmitted signal", Phys. Rev. Lett., vol. 76, 1996, pages 904-907.

[15] ANP3, http://www.it.dtu.dk/ el/ecs/anpnap.htm 